\title{
Consequences of obstetric fistula in sub Sahara African countries, from patients' perspective: a systematic review of qualitative studies
}

\author{
Debrework Tesgera Bashah ${ }^{1 *}$ (D), Abebaw Gebeyehu Worku²,3 and Mezgebu Yitayal Mengistu ${ }^{4}$
}

\begin{abstract}
Background: Women with fistula live in a state of distress and in fear of their future life. An obstetric fistula has a devastating impact on affected women and their families. The objective of this systematic review was to synthesize the evidence from published articles on the consequences of obstetric fistula on women who endure the condition.

Methods: The consequences were systematically reviewed from purely qualitative and mixed method primary studies. The literatures were searched through the search engines Google, Google scholar, Hinari using Pub Med data bases, and citation tracking. Relevant source of publications were searched for primary qualitative studies by formulating search protocol using related search terms. Time (articles published between January first of 2007 and 30th September 2016), participants (women who experienced obstetric fistula due to obstructed labor complications), types of study (purely qualitative and mixed method primary articles), findings (reporting consequences/impacts of obstetric fistula) were used as inclusion criteria. The quality appraisal tool for qualitative studies and the critical appraisal skills program were used to appraise the quality of the studies. The findings of sixteen studies were included in the review. The data were collected and then a thematic framework approach was applied for analysis.

Results: The thematic categories shared across most studies were related to the physical challenges of losing body control, women's social and family relationships, and the challenges of losing income. Obstetric fistula has far reaching consequences on women's physical well being, social and marital relationships, mental health and economic capacity. Fistula also challenged women coping abilities.

Conclusion: The consequences of obstetric fistula are far more than the visible medical condition. Little evidence is available on mental health, child and fertility issues, and coping mechanisms. Therefore, further researches shall be aimed at addressing the understudied area and suitable interventions shall be offered to improve women's overall quality of life.
\end{abstract}

Keywords: Challenges of incontinence, Obstetric fistula, Psychosocial experiences, Urogenital fistula, Vesicovaginal fistula

\section{Background}

Obstetric fistula is a preventable maternal morbidity that results from prolonged and obstructed labor [1]. It commonly occurs when there is Cephalo pelvic disproportion. Unless there is skilled obstetric intervention this disproportion creates pressure on the tissues and then

\footnotetext{
* Correspondence: debre2012@gmail.com

${ }^{1}$ School of Nursing, College of Medicine and Health Sciences, University of Gondar, P. O. Box 196, Gondar, Ethiopia

Full list of author information is available at the end of the article
}

prolonged ischemia will cause tissue necrosis leading to fistula formation [2]. It causes life-long disabilities and poor quality of life $[3,4]$. In the developed world it is very rare and faded away 100 years ago following improved obstetric care [5], while it remains the prevalent cause of maternal morbidity in the developing world $[6,7]$. It affects more than 2 million women worldwide, with at least 50,000 to 100,000 new cases occurring annually [8]. Among which the majority is from resource-poor countries where the health system is ineffective $[9,10]$. The majority

(c) The Author(s). 2018 Open Access This article is distributed under the terms of the Creative Commons Attribution 4.0 International License (http://creativecommons.org/licenses/by/4.0/), which permits unrestricted use, distribution, and reproduction in any medium, provided you give appropriate credit to the original author(s) and the source, provide a link to the Creative Commons license, and indicate if changes were made. The Creative Commons Public Domain Dedication waiver (http://creativecommons.org/publicdomain/zero/1.0/) applies to the data made available in this article, unless otherwise stated. 
of obstetric fistula cases are in Africa and Asia [1]. Continuous and uncontrollable leaking of urine and/or feces can lead to life-changing stigmatization of the women $[11,12]$. Therefore women with fistula live in a state of distress and a fear of their future life [13]. The consequence of obstetric fistula is devastating for those affected women and their families [14, 15]. Beyond the medical conditions, the social consequences are severe, and affected women are often ostracized from their community, divorced, abandoned, and remain childless $[16,17]$. Women living with fistula may be blamed by the community members for their condition, viewing it as punishment for sin or a venereal disease or curse [17]. The women are unable to participate in religious activities and social gatherings, and are considered unhygienic [18, 19].

The objective of this systematic review was to summarize and synthesize the evidence of the multidimensional consequences on women with obstetric fistula. It can therefore provide evidence for decision makers for intervention so as to improve women's quality of life.

\section{Methods}

\section{Search strategy}

The database searches used specified key terms to identify studies for potential inclusion in the review. The literature was searched through search engines Google, Google scholar, and Hinari, using Pub- Med data bases and citation tracking.

CoCoPopS protocol was formulated to identify articles Co: obstetric fistula impact/challenge; Co: developing world/sub-Saharan Africa; Pop: women with obstetric fistula; and S: primary qualitative and/or mixed method studies.

The terms were; "Obstetric fistula","vesicovaginal fistula", "Rectovaginal fistula", "Urogenital fistula", "challenges of fistula", "Consequences of fistula", "Psychosocial experience" of women were key words used to search relevant papers and the search protocol was as follows:

"Obstetric fistula" [MeSH Terms] OR "Obstetric fistula" [All Fields] OR"VVF" [MeSH Terms] OR "Vesico-vaginal Fistula[MeSH Terms]OR" "Rectovaginal Fistula" [MeSH Terms] OR "RVF" [MeSH Terms] OR "Urogenital fistula" [MeSH Terms] AND "Consequence" [MeSH Terms] OR"Consequence" [All Fields] OR "Challenges" [All Fields] OR "Lived experience" [All Fields] AND "Africa" [All Fields] OR "sub-Sahara Africa" [All Fields]. There were no language restrictions except for articles which did not have the "translate" option. As a result, one article was found in French and was excluded due to the irrelevance of its objective with the review objective. Predominantly, the review was based on a selection of published literature. Three steps were used to select papers for review. First, relevant titles and abstracts were identified from databases. In the second stage, screening and retrieving of full text articles were conducted. In the final step, after identifying papers that potentially meet the inclusion criteria, data extraction from relevant selected articles and qualitative reviews of the articles were done. Analysis was restricted to studies intended to explore the consequences of obstetric fistula on women with the condition.

\section{Selection of studies}

For studies that have an abstract identified in the database searches, the abstracts were reviewed to determine whether or not they should be included by using the following criteria for the inclusion and exclusion of papers.

\section{Phase I}

Topic: An article was included only if it discussed obstetric fistula and its potential consequences/experiences/ challenges on women with obstetric fistula.

Time: Articles published between January $1^{\text {st }} 2007$ and 30th September 2016 was included for the review.

Participants: Study participants had to be women who experienced obstetric fistula Rectovaginal fistula (RVF) or Vesicovginal fistula (VVF) due to obstructed labor complications.

Type of study: The primary articles of case studies, and purely qualitative and/mixed method studies, which used both qualitative and quantitative approach were included.

\section{Phase II}

Selected articles were read in their full document and included if only they reported the consequences/impacts of obstetric fistula regardless of respondents' repair status (whether the study was conducted before or after repair). Articles were excluded if there was no discussion of the impact/ challenge/experiences of fistula victims.

For each article included in phase II, the article information was entered into a structured data extraction form. The information included in the data extraction form included the name of the author, publication date, country, setting, study design, participant characteristics, and consequences identified (Table 1). The identified quality appraisal framework Critical appraisal skills Program (CASP) was used for each study included [20]. Selected studies were assessed with the listed criteria in CASP, such as clarity of the objectives, appropriateness of method used, clarity of the study context, appropriateness of the participant recruitment strategy to the aims of the research, data collection technique, relationship between researcher and participant (bias), consideration of 
ethical issues, whether data analysis was sufficiently rigorous, whether findings were clear, how much the study was valuable regarding its transferability, and contribution to knowledge and identifying areas of research gap (Additional file 1). Each study has scored good to poor in each criterion, with a quality rating score of high to low with respective percentage values. A total of 16 studies that met the inclusion criteria were included in the review.

The qualitative evidence was synthesized using thematic analysis. All themes identified in the primary studies were extracted. The thematic analysis allowed identification of major issues and helped to manage large data under each theme (Table 2). The steps were as follows:

1. Reading the document and identifying key issues and themes by relating to study objectives, contents of interview questions and respondents views and experiences;

2. Selecting similar themes from different studies in the same group and relabeling them with short descriptions;

3. Rearranging the data according to the appropriate part of the thematic framework to which they related, and

4. Using charts to define concepts, and to find associations between themes with a view to providing explanation of findings.

\section{Results}

A total of 127 citations were identified from the electronic search after removing duplicates. On review of the titles, 36 articles were discarded due to the irrelevance of the topic. On screening of the remaining 91 titles and abstracts, 54 were excluded based on the selection criteria. Nine were titles only and were not relevant to the objective of the review; and eight were annual or project reports. The remaining 37 studies were retrieved and read in full, of which 21 reports were excluded since they did not fulfill the eligibility criteria. 19 articles were quantitative studies and two articles were qualitative but reported other than what was intended, i.e. one reported experiences of women with another birth injury, near miss uterine rupture; and the other reported the impact of surgical treatment on the mental health of fistula victims. The process used to determine which studies should be included in the review is shown in PRISMA flow diagram (Fig. 1).

All included studies were conducted in Sub-Saharan Africa: two in Ethiopia [21, 22], five in Tanzania [11, 13, 23-25], one in Uganda and Tanzania [11], one in Eritrea [16], two in Uganda [26, 27] two in Nigeria [19, 28], one in Kenya [29],one in Ghana [30], and one in Malawi [31]. All research took place in treatment or rehabilitation facilities, except reports from Kenya and Malawi which were conducted in the community. Nine studies were conducted in urban settings and the other seven in rural settings. Nine studies used a qualitative methods approach, while the rest used a mixed method approach. The stated length of study ranged from two weeks to two years between 2010 and 2013. All included studies related to the same target population, i.e. women affected by fistula, and two studies additionally included family members/care givers $[13,31]$. Another two studies further incorporated key informants and experts in the field [11, 26]. Most studies used semi-structured interviews as a data collection tool, with the average study participants of 53 ranging from 8 to 137 respondents. The age of women included in the research ranged from 17 to 69 years. Nine studies reported the duration of fistula that ranged from one month to fifty two years.

The methodological quality of the included papers ranged from good to poor. The mean quality percentage score of the studies was $91 \%$. Unreliable recruitment strategies, poor data collection methods, unclear researcher participant relationships and unclear data analysis methods were the limitations of the poor quality studies.

The thematic categories shared across the most studies were related to the physical challenges of losing body control, the disturbance in family relationship and women's social association. Three studies included another theme, coping mechanism [22, 26, 32], and one study reported on mental health, marital relationships and child and fertility themes [31]. Some studies reported the loss of income source activities and medical conditions resulting from fistula (Table 3).

\section{Discussion}

The review o demonstrated that the consequences of obstetric fistula are beyond its visible medical conditions in sub-Saharan Africa. This offers summarized evidences on consequences related to physical conditions; women's social and marital relationships, economic in capabilities; mental health and challenges to coping mechanisms.

\section{Physical consequence}

Physical consequence was the core theme shared across most studies, described as loss of body control and the challenges faced to keep cleanness $[13,16,19,24,28,29$, 32]. Physical challenges include the emotional and medical problems of fistula which resulted from incontinence, such as genital sores, smells, wounds, pain, discomfort, exhaustion, and foot drop [21]. studies indicated that women with the condition were unable to afford hygiene keeping supplies and to cover medical fees therefore, they use herbs to sooth sores $[11,23]$. In order to control the leak some women restrict themselves from feeding as they used to in pre fistula period, and this resulted in weight loss [11]. Moreover, in order to prevent the smell, discomfort, and to stay clean women with obstetric fistula tend to 


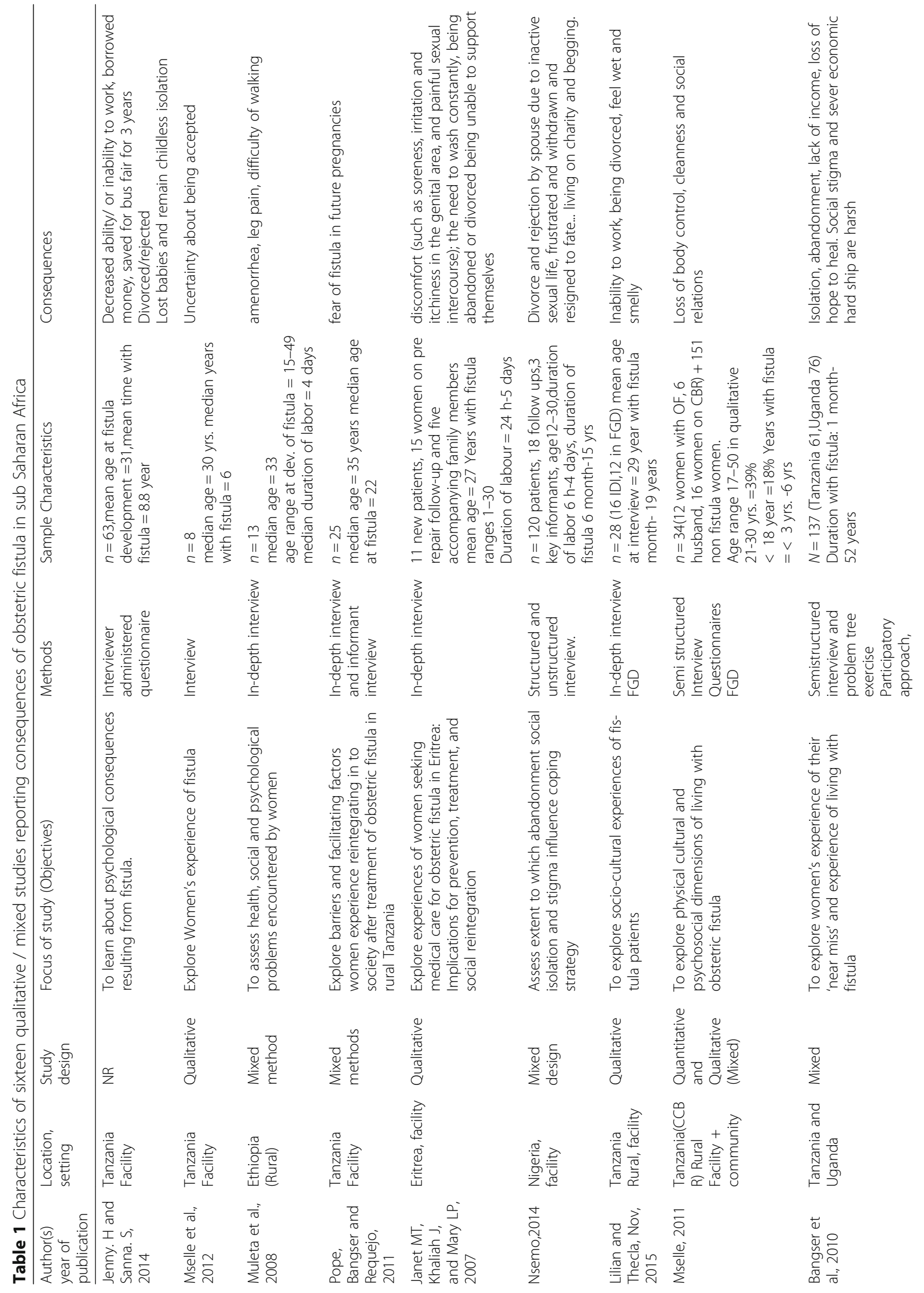




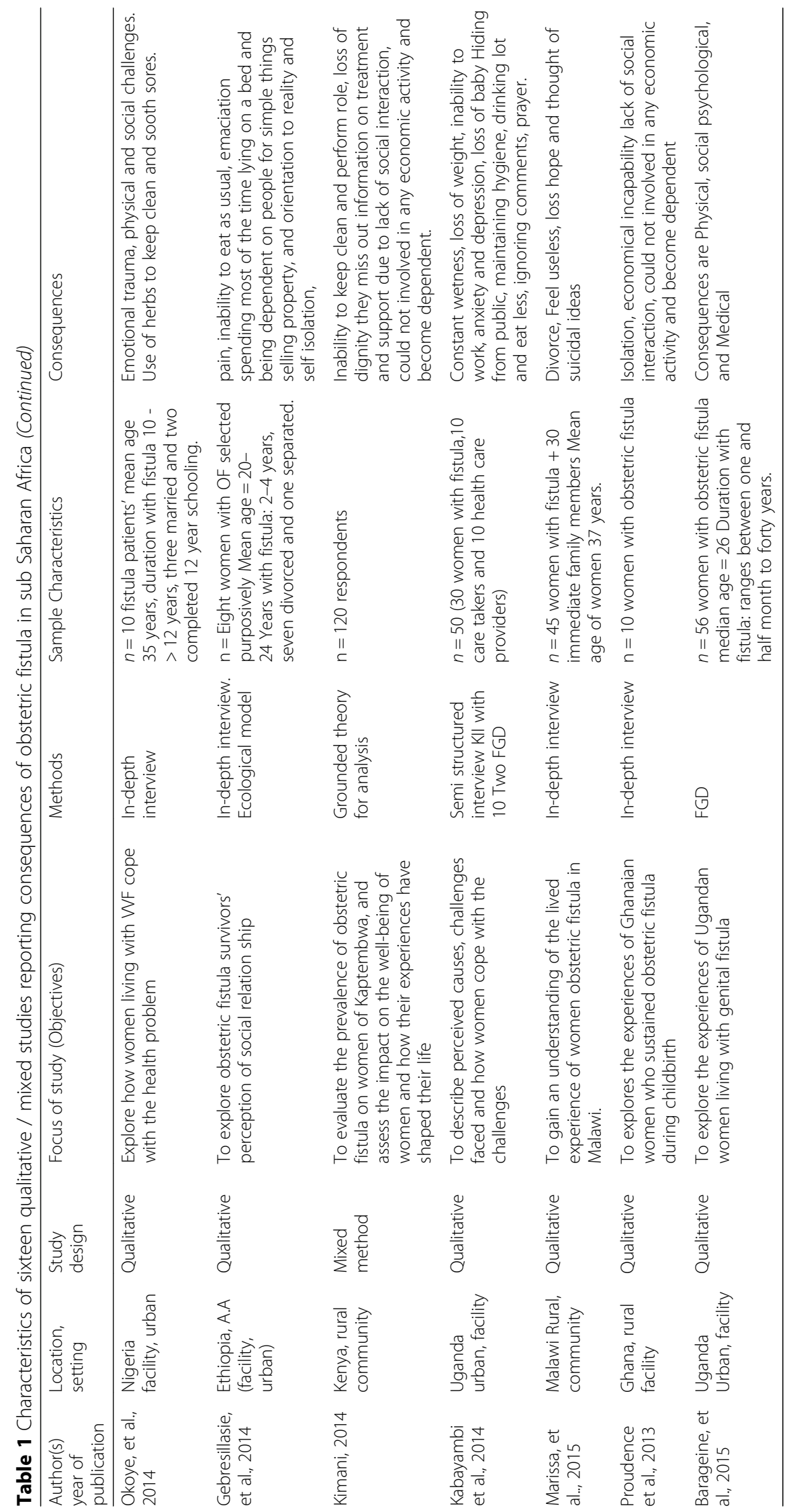




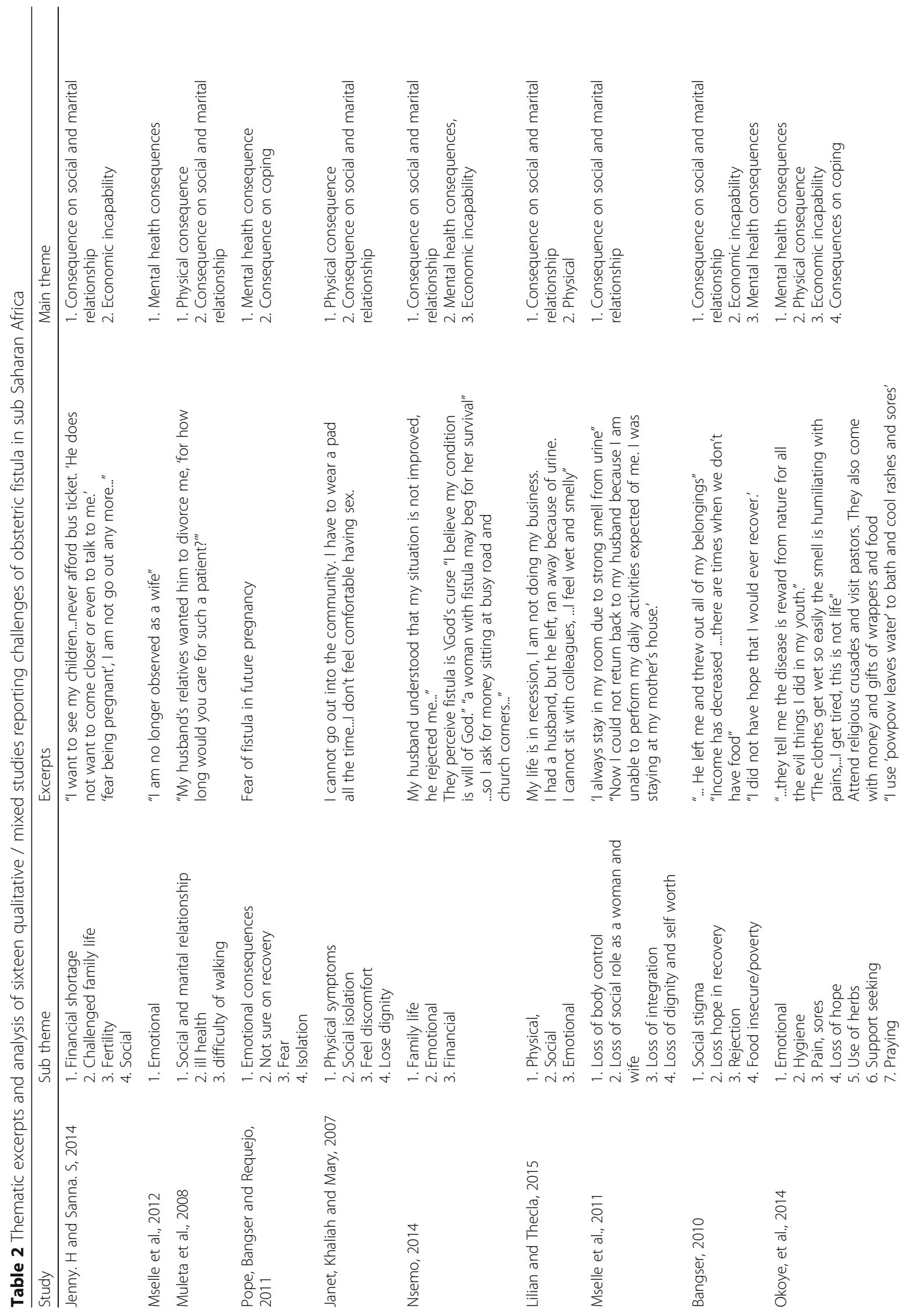


Bashah et al. BMC Women's Health (2018) 18:106

Page 7 of 12

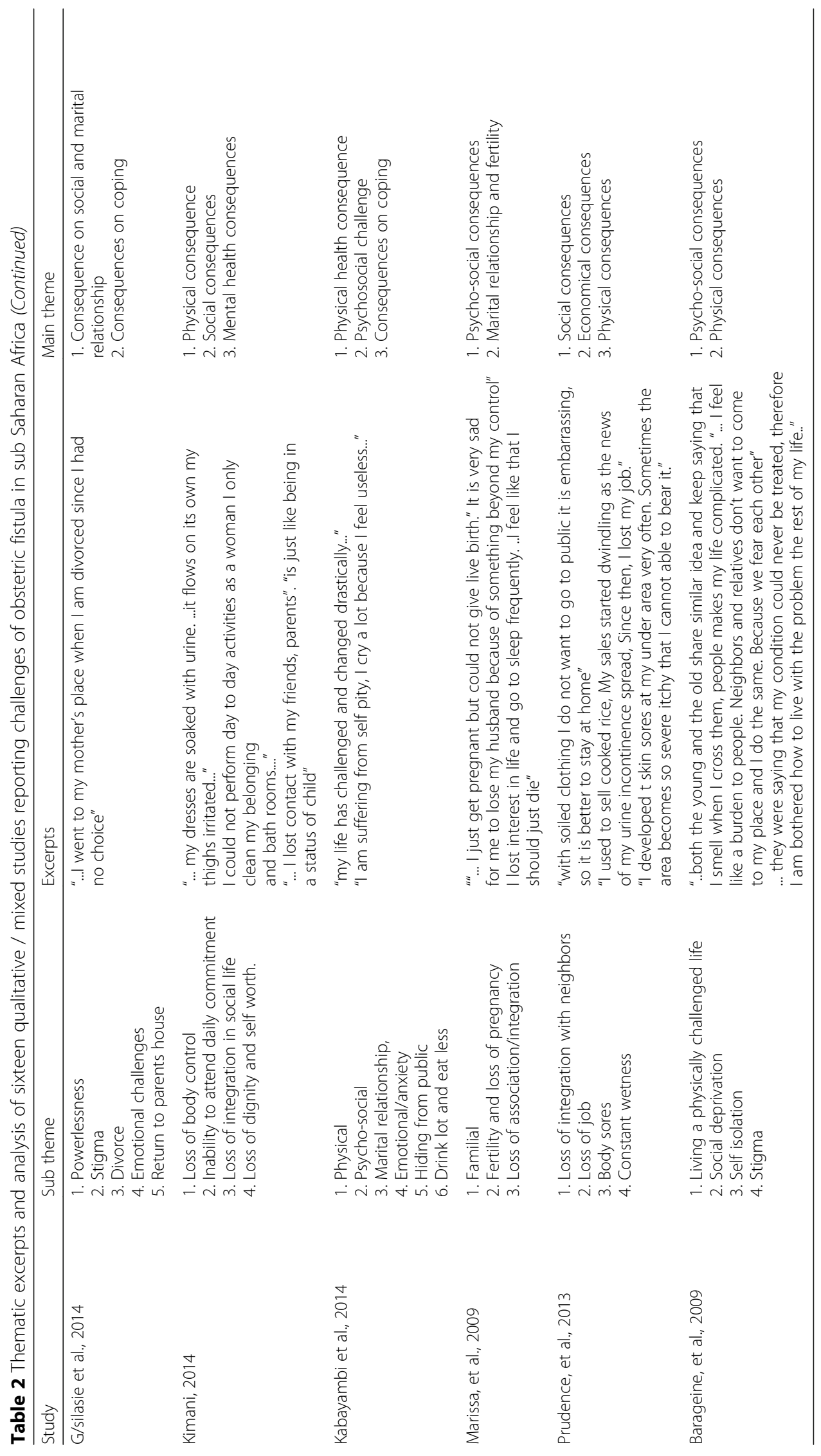




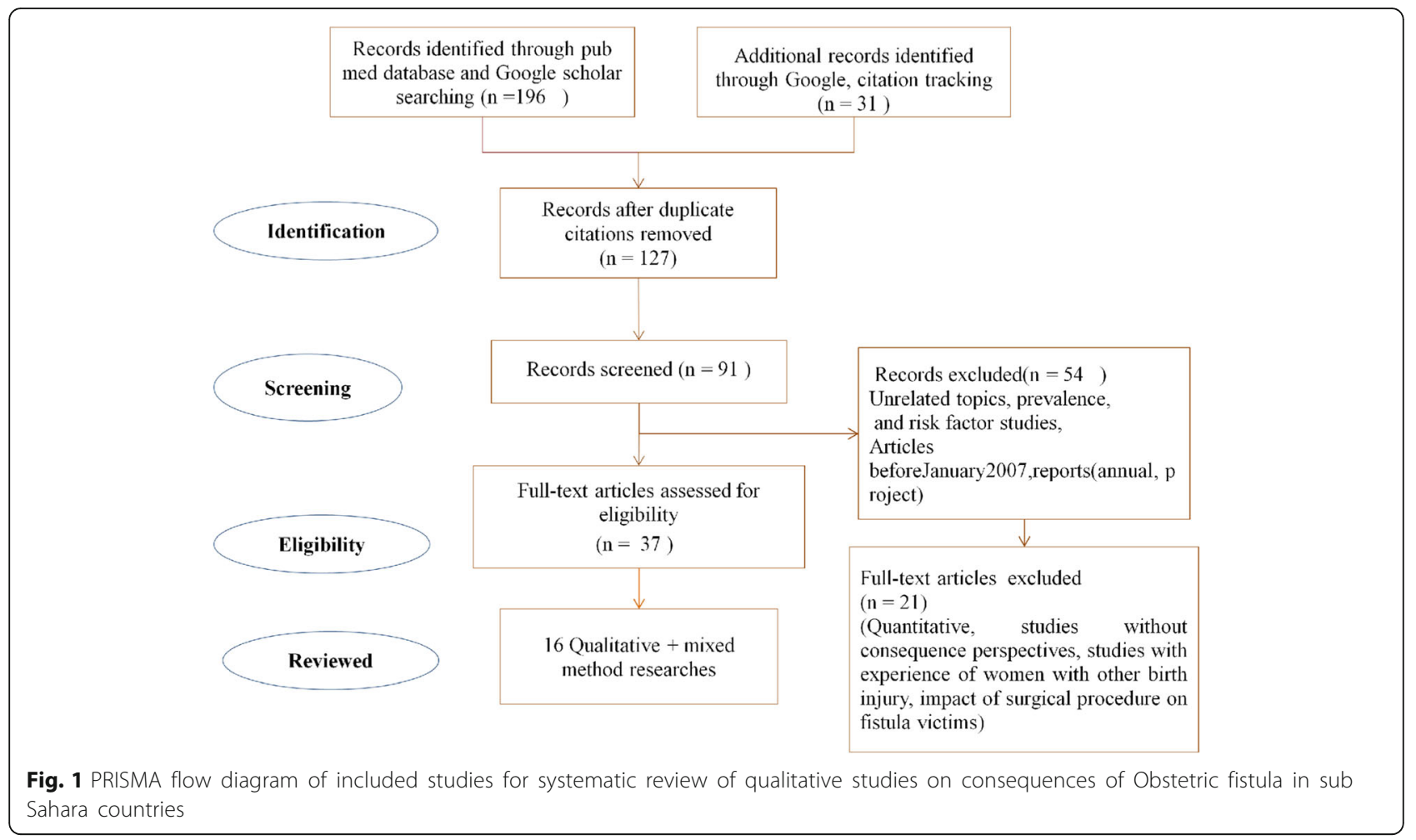

bath repeatedly; and they get bored of the frequency of washing $[13,32]$.

\section{Consequences on women's social and marital relation ship}

Most studies included marital and social relationships issues as the main theme $[11,13,19,22,23,26,29]$. It is a common event that fistula-affected women face divorce as they fail to satisfy their husband's sexual needs and/or fail to bear children. As the women become incapable of performing the family roles expected of them, they were perceived as "useless" beings. Therefore, they became neglected and abandoned. A woman reported that she was mistreated by her spouse after the fistula incident, "He left me and threw out all of my belongings" .....ever since I developed the condition, we have not been together as husband and wife. I have been left out here to care for the old lady (mother-in-law). Even after repair, different socio-cultural factors can hinder the acceptability of women who integrated back to the community [13, 26, 31]. A study in Malawi reported that remarriage was not difficult among divorced women with fistula, as long as the husband knows the problem prior to marriage [31]. However, the report might not represent all other women with fistula, as it was reported by one participant and also may not be true for all fistula women living across different countries. Except for this report from Malawi, the concept of keeping association was also a common theme of all reviewed papers. Seven (43\%) reported the faced discrimination and difficulty in maintaining social relationships. Unless they got an opportunity to obtain a repair service, women with fistula would not be considered as a woman and therefore, they lose their power and confidence [11]. Although few reported the presence of supportive husbands, most studies revealed experience of rejection, neglect and abandonment $[8,23,24,27,31]$.

\section{Economic incapability}

Loss of income source activities as a result of fistula was reported in some of the reviewed studies [22, 26, 27, 32]. Women with fistula could not get involved in gainful employment or activities that needed strict hygiene [32]. They also lost business because of the incontinence, and were self-employed in petty trading where they earned too little income. As a respondent from a Ghana study stated [32]: "... I used to sell cooked rice but my condition has obliged me to stop. My sales started dwindling as the news of my urine incontinence was heard". Therefore, sometimes they fell into deeper poverty and start to beg for survival [32]. In this way, fistula has challenged and contributed to disfigure image of women's health in developing countries.

\section{Mental health consequences}

This issue was addressed in few of the studies that reported loss of dignity, lack of support, and lack of power to seek care. Loss of hope, fear of future life, and feelings of dependency were stated as mental health problems 


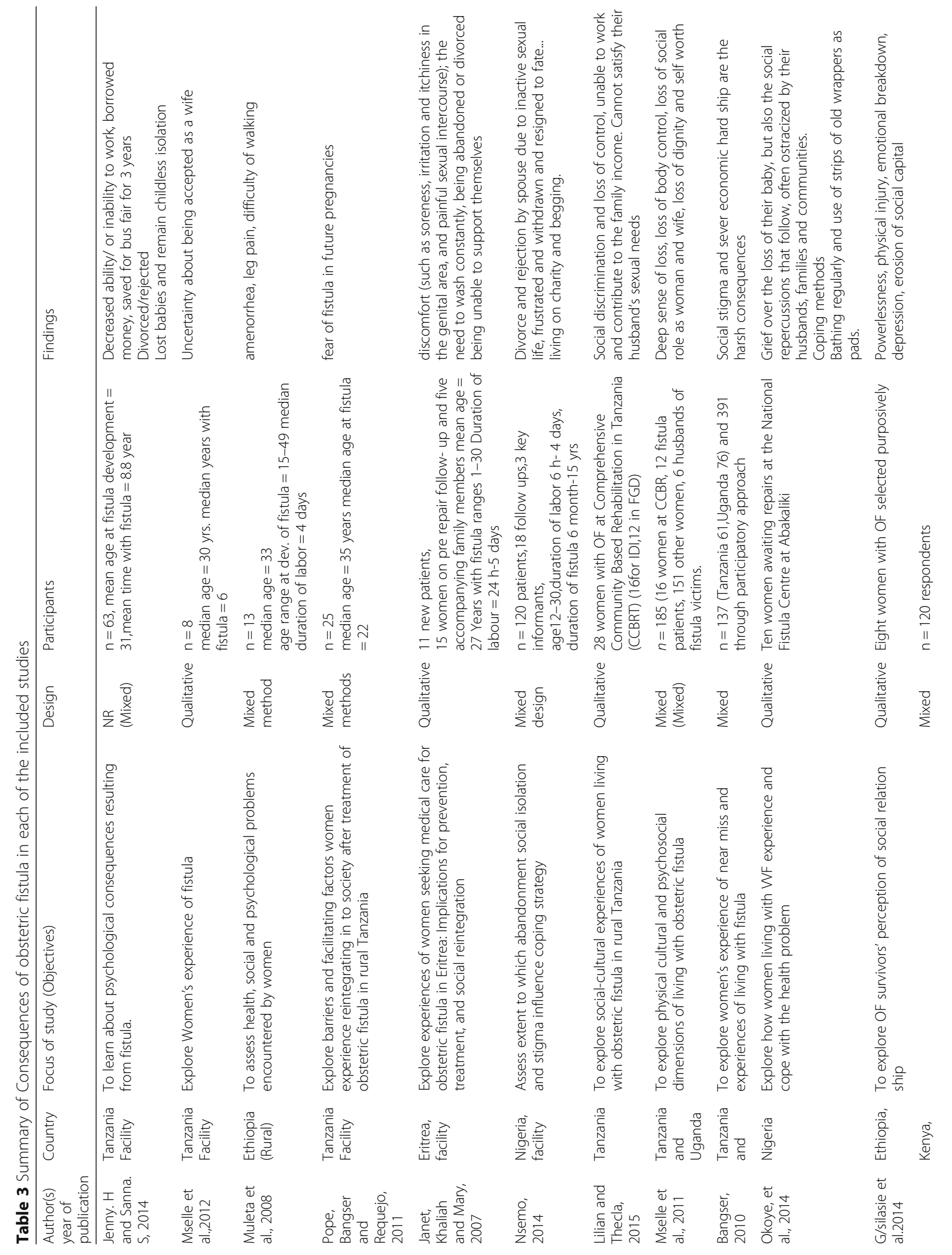




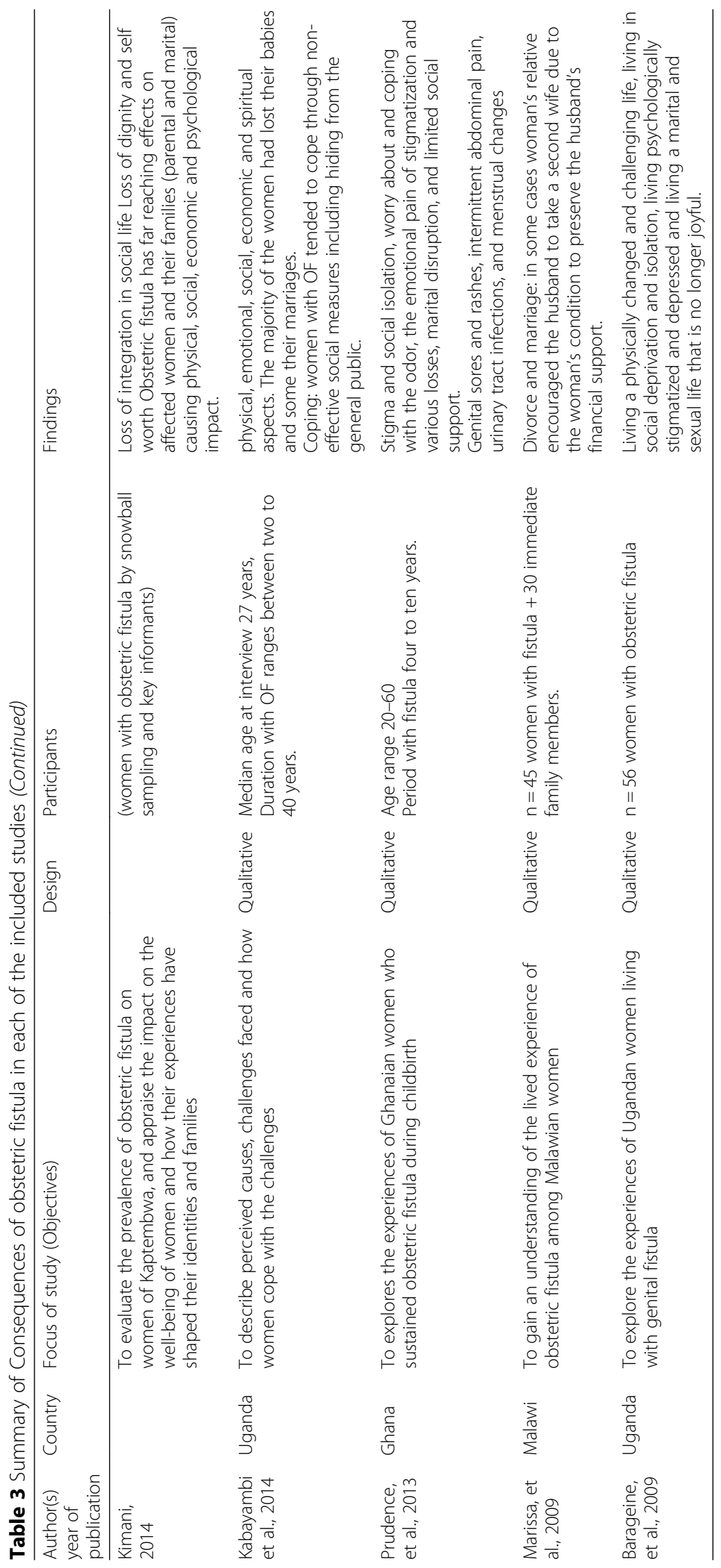


$[13,22]$. This challenges were emerged as the result of different interrelated problems such as lack of support and family care, physical or economical incapability to access care, and lack of information or knowledge about fistula care and treatment [28]. It might also result from the reactions and comments of people with a poor understanding of the condition $[19,29]$. Perceived causes of fistula and social stigma has caused psychological morbidity to women $[19,23,27]$.

\section{Coping experiences}

Keeping strict hygiene, washing with scented soap, the use of pieces of old cloth as a sanitary pad, and the use of herbs for cleaning, were reported as common coping mechanisms [22, 26, 32]. In some cases, ineffective practices for coping such as isolation, hiding, drinking a lot and eating less or changing feeding habits were undertaken [19]. Which may result in to other health problems such as depression and malnutrition [23, 27]. Women were used to discuss among themselves as a means for getting relief and those who got training tended to accept the reality in order to cope in a better way and keep themselves busy doing hand crafts [22].

Limited geographical coverage of the reviewed literatures might affect the transferability of the findings. Most of the included researches were conducted in facility settings, which mean that the voice of those women remaining at home, with perhaps more challenges, was lacking. The search strategy has not included subscription databases such as MEDLINE, EMBASE, and Scopus.

\section{Conclusion}

This review highlighted that the consequences of obstetric fistula are far more than the visible medical condition itself. Little evidence is available on mental health, child and fertility issues, and coping mechanisms. Therefore, further research shall be aimed at addressing the understudied area, and suitable interventions shall be offered to improve women's overall quality of life.

\section{Additional file}

Additional file 1: Appraisal tool adopted from CASP used to assess quality of studies included in the review. (DOCX $49 \mathrm{~kb}$ )

\section{Abbreviations}

CASP: Critical Appraisal Skills Program; CoCoPopS: Condition Context Population Study design; PRISMA: Preferred Reporting Items for Systematic review and Meta-Analyses; RVF: RectoVaginal Fistula; WF: VesicoVaginal Fistula; WHO: World Health Organization

\section{Acknowledgements}

The authors would like to forward their deepest gratitude to Institute of Public Health at University of Gondar for providing the opportunity and making arrangements to conduct this review.

\section{Authors' contributions}

DT carried out the review starting with article searching, screening, data extraction to analysis of data and drafting of the manuscript. AG participated in appraisals and critical reviews of the manuscript. MY participated in data screening, appraisals and commenting on the draft manuscript. All authors read and approved the final draft of the manuscript.

\section{Competing interest}

The authors declare that they have no competing interests.

Ethics approval and consent to participate

Not applicable.

Consent for publication

Not applicable.

\section{Publisher's Note}

Springer Nature remains neutral with regard to jurisdictional claims in published maps and institutional affiliations.

\section{Author details}

${ }^{1}$ School of Nursing, College of Medicine and Health Sciences, University of Gondar, P. O. Box 196, Gondar, Ethiopia. ²Department of Reproductive Health, Institute of Public Health, College of Medicine and Health Sciences, University of Gondar, Gondar, Ethiopia. ${ }^{3}$ Amhara National Regional State Health Bureau, Bahir Dar, Ethiopia. ${ }^{4}$ Department of Health Service Management and Health Economics, Institute of Public Health, College of Medicine and Health Sciences, University of Gondar, Gondar, Ethiopia.

Received: 20 July 2017 Accepted: 8 June 2018

Published online: 20 June 2018

\section{References}

1. Capes T, Ascher-Walsh AC, Brodman M. Obstetric fistula in low and middle income countries. Mount Sinai Journal of Medicine: A Journal of Translational and Personalized Medicine. 2011:78(3):352-61.

2. Ryan F. The typical story of obstetric fistula : the need to enhance awareness, action \& funds. 2014(17).

3. Kalembo FW, Zgambo M. Obstetric Fistula: A hidden public health problem in Sub-Saharan Africa. Arts and Social Sciences Journal. 2012. https://doi. org/10.4172/2151-6200.1000041.

4. Abrams P, Ridder Dd, deVries C, Sohier Elneil, Esegbona G, Mourad S, et al. obstetric fistula in the developing world. ICUD (international consultation on urological Diseases). 2010

5. Langkilde N, Pless T, Lundbeck F, Nerstrom B. Surgical repair of vesicovaginal fistulae-a ten-year retrospective study. Scand J Urol Nephrol. 1999:33(2):100-3.

6. Wall L, Arrowsmith S, Briggs N, Browning A and Lassey A. The obstetric vesicovaginal fistula in developing world. 2004.

7. Browning A, Patel T. FIGO initiative for the prevention and treatment of vaginal fistula. Int J Gynaecol Obstet. 2004;86(2):317-22.

8. Bala S. Birth and sorrow: The psycho-social and medical consequences of Obstetric fistula wwwinternationalscholarsjournalsorg @. International Scholars Journals. 2014;2(2):055-65.

9. Almaw TF, Keysers L, Chhachhi A. From Trauma to Rehabilitation and Reintegration: Experiences of Women Facing the Challenges of Obstetric Fistula in Addis Ababa. Ethiopia: November; 2010.

10. Zhengx A, Frank W, Ander J. Obstatric fistula in low income countries. International journal of gyneacology and obstatrics. 2008;104:85-9.

11. Bangser M, Manisha M, Janet S, Chris D, Catherine K, et al. Childbirth experiences of women with obstetric fistula in Tanzania and Uganda and their implications for fistula program development. Int Urogynecol J. 2011;22:91-8.

12. Roush KM. Social implications of obstetric fistula: an integrative review. Journal of Midwifery and Women's Health. 2009;54:21-33.

13. Lilian TM, and, Thecla WK. living with constant leaking of urine and odour: thematic analysis of socio-cultural experiences of women affected by obstetric fistula in rural Tanzania. BMC Womens Health 2015;15:107.

14. Kayondo M, Wasswa S, Kabakyenga J, Mukiibi N, Jude Senkungu, Stenson A, et al. Predictors and outcome of surgical repair of obstetric fistula at a 
regional referral hospital,Mbarara, western Uganda. 2011;11:(23). https:// bmcurol.biomedcentral.com/articles/10.1186/1471-2490-11-23.

15. Mutambra J, L M, Muchichewa. Towards promotion of maternal health: the psychological impact of obstetric fistula on wumen in Zimbabwe. International journal of Asian social science towards promotion of maternal health. 2013;3(1):229-39.

16. Janet MT, Khaliah J, Mary LP. Experiences of women seeking medical care for obstetric fistula in Eritrea: implications for prevention, treatment, and social reintegration. Global Public Health: An International Journal for Research, Policy and Practice. 2007;2(1):64-77.

17. Yeakey MP, Chipeta E, Taulo F, Tsui AO. The lived experience of Malawian women with obstetric fistula. Cult Health Sex. 2009;1 1(5):499-513.

18. Ahmed S, Genadry R, Stanton C, Lalonde a. Dead women walking: neglected millions with obstetric fistula. Int J Gynecol Obstet. 2007;99(Suppl 1):S1-3.

19. Okoye UO, Emma NE, Perpetual LT. Living with vesico vaginal fistula: experiences of women awaiting repairs in Ebonyi state, Nigeria. Tanzania Journal of Health Research. 2014;16(4):322-8.

20. Hannes K. Chapter 4: critical appraisal of Qual Res 2011. In: Supplementary Guidance for Inclusion of Qualitative Research in Cochrane Systematic Reviews of Interventions [Internet]. Cochrane Collaboration Qualitative Methods Group.

21. Muleta M, Hamlin C, Fantahun M, Kennedy RC, Tafesse B. Health and social problems encountered by treated and untreated obstetric fistula patients in rural Ethiopia. Journal of obstetrics and Gyneacology. 2008;30(1):44-50

22. Gebresilase YT. A qualitative study of the experience of obstetric fistula survivors in Addis Ababa, Ethiopia. Int J Womens Health. 2014:6:1033-43.

23. Mselle L, T Karen M Moland, Evjen-Olsen B, Abu M, and, Thecla WK. "I am nothing": experiences of loss among women suffering from severe birth injuries in Tanzania. BMC Womens Health 2011;11(49).

24. Hsiung J, Savbäck S, Olola O, Andersson R. Long-time Suffering from Psychosocial Consequences A Problem for Women with Vaginal Fistula in Moshi. Tanzania. [research article]: In press; 2014.

25. Mselle L, Teddy, Rnm a, Evjen-Olsen B, Karen M, Moland, Polit C, Mvungi a, et al. hoping for a normal life again: reintegration after fistula repair in rural Tanzania. J Obstet Gynaecol Can. 2012;34(10):927-38

26. Kabayambi J, Baragein JK, Matovu JKB, Beyeza J, Ekirapa E, et al. Living with obstetric fistula: perceived causes, challenges and coping strategies among women attending the fistula Clinic at Mulago Hospital, Uganda. International Journal of Tropical disease and health. 2014;4(3):352-61.

27. Barageine JK, Kashesya JB, Byamugisha JK, Tumwesigye NM, Almroth L, et al. "I am alone and isolated": a qualitative study of experiences of women living with genital fistula in Uganda. BMC Womens Health. 2015;15:73.

28. Nsemo AD. Influence of Abandonment, Stigmatization and Social Isolation on the Coping Strategies of Women with Vesico Vaginal Fistula in Akwa lbom State, Nigeria. http://dxdoiorg/104172/2167-11681000159. 2014;3(159):2-8.

29. Kimani MZ, Omondi O, and, Anthony K. The prevalence and impact of obstetric fistula on women of Kaptembwa Nakuru, Kenya. International Journal of Applied Science and Technology 2014; 4 (273).

30. Prudence P, Mwini-nyaledzigbor, Alice AA and Beryl PF. Lived Experiences of Ghanaian Women With Obstetric Fistula. http://dxdoiorg/101080/ 073993322012755981. 2013;34(6):440-460.

31. Marissa PY, Effie CT, Tsui AO. The lived experience of Malawian women with obstetric fistula. Culture, Health and Sexuality: An International Journal for Research, Intervention and Care. 2009;11(5):499-513.

32. Ahmed S, Holtz S. Social and economic consequences of obstetric fistula: life changed forever? Int J Gynecol Obstet. 2007;99:510-5.

\section{Ready to submit your research? Choose BMC and benefit from:}

- fast, convenient online submission

- thorough peer review by experienced researchers in your field

- rapid publication on acceptance

- support for research data, including large and complex data types

- gold Open Access which fosters wider collaboration and increased citations

- maximum visibility for your research: over $100 \mathrm{M}$ website views per year

At BMC, research is always in progress.

Learn more biomedcentral.com/submissions 